\title{
APPLICATION OF HURDLE TECHNIQUE TO PRESERVE FRESH SCRAPED COCONUT AT AMBIENT AND REFRIGERATED STORAGE
}

\author{
K.D.P.P.GUNATHILAKE \\ Coconut Research Institute, Bandirippuwa Estate, Lunuwila.
}

(Accepted: 22 December 2005)

\begin{abstract}
Studies were conducted to preserve freshness of scraped coconut by applying the Hurdle Technique. The preliminary experiment was carried out to identify suitable humectant (to reduce water activity to $<0.94$ ) and the level of acidulent to be added (to reduce the $\mathrm{pH}$ to $<4.5$ ). The main study consisted of simple mixing of blanched scraped coconut with a combination of additives comprising of sodium chloride (as humectant), citric acid (as acidulent), tri sodium citrate (as buffer), and sodium benzoate $0.05 \%$ (as anti microbes) and Butylated Hydroxy Anisole (BHA), $0.02 \%$ on fat basis (as antioxidant), equilibrate for two hours, packing in LDPE/Nylon flexible pouches. The packed samples were stored at ambient $\left(30 \pm 2^{\circ} \mathrm{C}\right)$ and refrigerated $\left(5 \pm 2^{\circ} \mathrm{C}\right)$ temperatures for a period of three months and were analyzed for physico-chemical and sensory properties.
\end{abstract}

It was found that use of sodium chloride at $3 \%$ and citric acid at $0.3 \%$ was effective as humectant and acidulent respectively. During storage it was found that coconut in ambient storage showed significant $(\mathrm{p}<0.05)$ increase in free fatty acids and Thiobarbituric acid values after the first month, this could be due to the photo oxidation of fat in the transparent pouches. Low free fatty acids and TBA values were observed under refrigerated conditions. Colour measurements (" $L$ " and " $b$ " values) showed a significant $(p<0.05)$ difference after the first month of storage at ambient temperature and remained unchanged within the study period under refrigerated conditions. Microbiological studies showed that the total plate count in the coconut is not significant under both storage conditions within three months period and thereby indicating the hurdles to be effective against microorganisms. Sensory evaluation showed that the product remained acceptable up to one month at ambient temperature and minimum of three months at refrigerated temperature.The results indicated that application of combination preservation technique on fresh coconut gratings would extend the shelf life by one month at ambient conditions and by three months at refrigerated conditions.

Key words: Ambient storage, coconut, Hurdle Technique, preserve, shelf life

\section{INTRODUCTION}

Mature coconut has a special place in Sri Lankan culinary and is used in grated or milk form. Coconut is known to become rancid relatively easily and difficult to preserve in the fresh form for long periods as it is prone to microbial spoilage within few days. ${ }^{1}$ Fresh coconut in grated or scraped form is one of the products in demand by modern society. With the introduction of the Hurdle Concept, there is now worldwide interest in the application of Hurdle Technology in foods, based on combination preservation techniques using two or more factors, none of which is individually sufficient to prevent microbial spoilage. ${ }^{2}$ The present combined methods approach or the Hurdle Concept was developed to determine conditions needed to limit the growth of microorganisms in non sterile foods. This involves manipulating various growth controlling parameters in a manner such that growth will not occur. Each parameter is a "hurdle" to microbial growth. Common hurdles include physical heat treatment, water activity, $\mathrm{pH}$ and preservatives when used together, hurdles interact synergistically enabling the use of lower intensity of each factor than would be necessary if each were used alone. ${ }^{2}$ The different treatments called as hurdles are used in preventing chemical as well as microbiological deterioration of the food product. A combination of these hurdles is very effective, while individually each hurdle is ineffective in protecting food from deterioration. ${ }^{3}$ Main objective of this experiment was to develop a method to preserve the fresh coconut in the "ready to serve" form using a combination preservation technique.

\section{METHODS \& MATERIALS}

Fully matured coconuts were collected from the plantations of Coconut Research Institute, Lunuwila. Preliminary experiments were carried out to determine the levels of humectant, acidulent and preservatives. In the second stage, 30 coconuts were soaked in a $100 \mathrm{ppm}$ sodium hypochlorite $(\mathrm{NaOCl})$ solution for $1 \mathrm{~min}$, washed thoroughly, broken into two halves and the white kernel grated by an electric coconut scraper (Local brand known as "Odiris") leaving behind 
the brown testa. 'The grated coconut was subjected to steam blanching for $3 \mathrm{~min}$. The blanched grated coconut was then mixed with salt (3\%), citric acid $(0.3 \%)$, tri sodium citrate $(0.1 \%)$, sodium benzoate $(0.05 \%)$ and Butylated Hydroxy Anisole (BHA) $(0.02 \%)$ and allowed to equilibrate for $2 \mathrm{~h}$. The prepared coconut gratings were packed in Nylon/ LDPE pouches ( $500 \mathrm{~g} /$ pouch). The packed samples were stored at ambient $\left(30+2^{\circ} \mathrm{C}\right)$ and refrigerated $\left(5+2^{\circ} \mathrm{C}\right)$ temperatures (10 samples per storage) for a period of three months and analyzed for physicochemical and organoleptic properties at monthly intervals

Moisture content, free fatty acids, thiobarbituric acid values were determined as per the Association of Official Analytical Chemists (AOAC) method 4, colour ( $\mathrm{L}, \mathrm{b})$ was determined by Colour Deference Meter (ZE-2000, Nippon Denshku). Water activity was determined by measuring the Equilibrium Relative Humidity (ERH) using the Electric Humidity Sensor (CHS-UPS, TC2 TDK) and the $\mathrm{pH}$ was measured using a standard pH Meter (TOA, IM-405). "Pol Sambol" (Sri Lankan dish) was prepared to evaluate the sensory properties of preserved coconut using the nine point Hedonic Scale (9-like extremely and 1-dislike extremely). Forty untrained panelists were used for the sensory analysis. Pour plate technique was used to determine total plate count and was carried out according to the method described in AOAC. ${ }^{4}$ Coconut milk was extracted from $100 \mathrm{~g}$ treated coconut by adding $200 \mathrm{ml}$ water and salt level in the aqueous extract was determined by a method described previously. ${ }^{5}$

\section{RESULTS AND DISCUSSION}

Different levels of salt (sodium chloride) were examined to reduce the water activity to 0.94 without adversely affecting the organoleptic properties. It was found that $3.0 \%$ salt was optimum (Table 1 ).

The limiting water activity and $\mathrm{pH}$ for most food poisoning bacteria including salmonellae and clostridia in food is 0.95 and 4.5 respectively. ${ }^{6}$ Table 1 shows that it is difficult to reduce the water activity further because of alteration of organoleptic properties. Salt at $3.0 \%$ was identified as a humectant to be used. It was found that use of $3 \%$ salt would not affect the sensory properties of the products prepared with treated coconut. Milk extracted with treated coconut contains about $0.8-0.9 \%$ salt and $230 \mathrm{ml}$ coconut milk (first and second extract) can be extracted with $100 \mathrm{~g}$ treated coconut scrapings. This amount of milk is sufficient to prepare a curry to serve four to five persons. According to the Food Standards Agency of UK, maximum daily intake should be 6 g per adult. ${ }^{7}$

It was found that citric acid and tri sodium citrate at $0.3 \%$ and $0.1 \%$ respectively is adequate to reduce the $\mathrm{pH}$ of coconut up to 4.5 . Since

Table 1: Effect of different salt and sugar levels on water activity of coconut gratings

\begin{tabular}{ccl}
\hline Humectant & Water activity & Organoleptic properties \\
\hline Salt & & \\
$1 \%$ & $>0.94$ & palatable \\
$2 \%$ & $>0.94$ & tolerable saltiness \\
$3 \%$ & 0.93 & tolerable saltiness \\
$4 \%$ & 0.92 & saltiness not tolerable \\
Sugar & & \\
$5 \%$ & 0.98 & sweet \\
$10 \%$ & 0.98 & sweet \\
$15 \%$ & 0.98 & sweet \\
$20 \%$ & 0.96 & sweet \\
$25 \%$ & 0.95 & sweet \\
\hline
\end{tabular}


tri sodium citrate acts as a buffering salt, in combination with acids it buffers the high acidic flavour of the fresh scraped coconut. In solutions where the $\mathrm{pH}$ must be altered, it is usually desirable to stabilize the $\mathrm{pH}$ at a desired level through a buffer system. ${ }^{8}$ BHA at $0.02 \%$ (allowable limit) on fat basis as antioxidant was used. Sodium benzoate at $0.05 \%$ can be used as an antimicrobial agent as effective concentration (EC) limit is $0.015-0.5 \%$ and the Acceptable Daily Intake (ADI) for sodium benzoate at present is $0-5 \mathrm{mg} / \mathrm{Kg}$ body weight. ${ }^{9}$ However, frequent consumption of coconut preserved by this method may be harmful to children and may lead to a higher than acceptable intake in adults.

Table 2 gives the quality characteristics of scraped coconut during the three months of storage under ambient and refrigerated conditions. In hydrolytic reactions catalyzed by lipases of foods or of microorganisms, the moisture and catalytic agents are the factors causing the hydrolytic rancidity and the free fatty acids (FFA) formed on hydrolysis are due to fragmentation of long chain fatty acids to short chain fatty acids. Therefore blanching was carried out to inactivate the lipases. This heat treatment together with BHA extended the shelf life of the gratings by delaying the rancidity development. BHA is a food grade antioxidant and it works more efficiently when combined with other additives. ${ }^{1}$ It was found that coconut gratings under ambient storage showed significant $(\mathrm{p}<0.05)$ increase in free fatty acids and the thiobarbituric (TBA) values after the first month. This could be due to photo oxidation of fat in the transparent pouches. Lower values of FFA and TBA were observed under refrigerated conditions during the entire study period when compared with samples stored under ambient conditons. A similar trend has been observed in previous studies. ${ }^{1}$ Changes in colour measurements, visual lightness ( $\mathrm{L}$ ) and yellowness (b) of preserved coconut under ambient conditions was significant $(p<0.05)$ while it was insignificant under refrigerated conditions. This could be due to the non enzymic browning. The storage data revealed that the increase of total plate count in coconut gratings is not significant under both storage conditions within the study period, thereby indicating that the hurdles were effective against bacteria, yeast and mold. It has been observed that

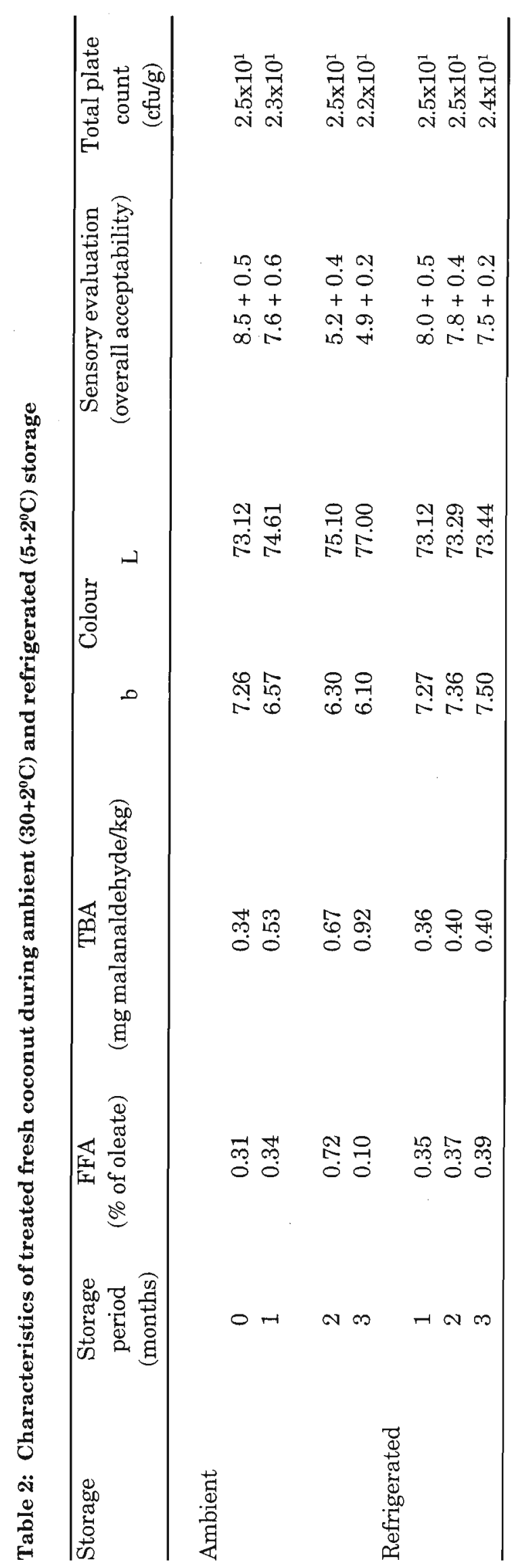


different hurdles in preservation may act synergistically. ${ }^{3}$ Thus reduction of water activity up to about 0.94 would be sufficient to suppress the growth of microorganisms while using other factors such as low $\mathrm{pH}$ and mild heat treatment.

Organoleptic evaluation indicated that treated scraped coconut was acceptable for up to one month. In the case of ambient storage after one month, acceptability reduces significantly due mainly to changes in colour. Treated coconut can be kept for about three months under refrigerated storage without significant changes in the organoleptic properties. The preserved fresh coconut gratings were found suitable for the preparation of dishes such as pol sambol, traditional Sri Lankan curries etc.

\section{CONCLUSION}

Application of Hurdle Technique on fresh coconut gratings extends the shelf life by one month at ambient conditions $\left(30+2^{\circ} \mathrm{C}\right)$ and by three months at refrigerated conditions $\left(5+2{ }^{\circ} \mathrm{C}\right)$.

\section{References}

1. Kumar R., Manimegalani G. \& Neelakantan S.(1996). Techniques to preserve the freshness of the coconut kernels. Indian Food Packer 50(2): 32-40.
2. Leistner L \& Gorris L.G.M. (1995). Food preservation by Hurdle Technology. Trends in Food Science and Technology 6: 41-46.

3. Webster S.N., Foowler D.R. \& Cooke R.D. (1985). Control of a range of food related micro organisms by a multi parameter preservation technique. Journal of Food Technology 20: 311-31.

4. AOAC (1995). Methods of analysis. $5^{\text {th }}$ Edition. Association of Official Analytical Chemists, Washington DC.

5. Pearson. D. (1973). Laboratory Techniques in Food Analysis, Butterworth \& Co. (Publishers) Ltd.

6. Jay J.M.I. (1996). Modern Food Microbiology. $5^{\text {th }}$ Edition, Chapman and Hall New York.

7. Food Standards Agency (2005 salt- http:// www.salt.gov.uk/index.shtml.

8. Fenema O.R.(1995). Food Chemistry, $3^{\text {rd }}$ Edition, Marcel Dekker Inc., USA.

9. JECFA (1997). Summary of evaluations performed by the Joint FAO/WHO Expert Committee on Food Additives. http:// www.inchem.org/documents/jecfa/jeceval/ jec_173.htm. 